\title{
The Dutch Healthy Diet index (DHD-index): an instrument to measure adherence to the Dutch Guidelines for a Healthy Diet
}

\author{
Linde van Lee*, Anouk Geelen, Eveline J C Hooft van Huysduynen, Jeanne H M de Vries, Pieter van't Veer
} and Edith J M Feskens

\begin{abstract}
Background: The objective was to develop an index based on the Dutch Guidelines for a healthy Diet of 2006 that reflects dietary quality and to apply it to the Dutch National Food Consumption Survey (DNFCS) to examine the associations with micronutrient intakes.

Methods: A total of 749 men and women, aged 19-30 years, contributed two 24-hour recalls and additional questionnaires in the DNFCS of 2003. The Dutch Healthy Diet index (DHD-index) includes ten components representing the ten Dutch Guidelines for a Healthy Diet. Per component the score ranges between zero and ten, resulting in a total score between zero (no adherence) and 100 (complete adherence).

Results: The mean \pm SD of the DHD-index was $60.4 \pm 11.5$ for women and $57.8 \pm 10.8$ for men (P for difference $=0.002$ ). Each component score increased across the sex-specific quintiles of the DHD-index. An inverse association was observed between the sex-specific quintiles of the DHD-index and total energy intake. Calcium, riboflavin, and vitamin E intake decreased with increasing DHD-index, an inverse association which disappeared after energy adjustment. Vitamin $C$ showed a positive association across quintiles, also when adjusted for energy. For folate, iron, magnesium, potassium, thiamin, and vitamin B6 a positive association emerged after adjustment for energy.

Conclusions: The DHD-index is capable of ranking participants according to their adherence to the Dutch Guidelines for a Healthy Diet by reflecting variation in nine out of ten components that constitute the index when based on two 24-hour recalls. Furthermore, the index showed to be a good measure of nutrient density of diets.
\end{abstract}

Keywords: The Netherlands, Index, Dietary patterns, Dietary guidelines

\section{Introduction}

Diets have a complex nature, as foods and nutrients are consumed in combinations which can induce interactions and synergies between dietary components. Dietary pattern analysis, therefore, is assumed a more appropriate approach for investigating diet-disease associations than focusing on a single food or nutrient [1-4].

One approach of assessing dietary patterns is to construct an a priori dietary index. These indices are mainly based on national or international dietary recommendations, which are designed to decrease the risk of chronic

\footnotetext{
* Correspondence: Linde.vanLee@wur.nl

Division of human Nutrition, Wageningen University, 8129, $6700 \mathrm{EV}$, Wageningen, The Netherlands
}

diseases and nutrient deficiencies [5,6]. Indices can be used to measure dietary quality in populations and monitor it over time [7] or measure changes in diets in intervention studies [8]. Furthermore, in epidemiological studies an index can be used to investigate the dietdisease associations [9]. Additionally, confounding by diet can be controlled through the use of a dietary pattern variable or a diet index score [10]. A well-known example of an index is the American Healthy Eating Index-2005 (HEI-2005) [11,12]. This index has been associated with, health outcomes [13], and has been used as monitoring tool in American populations [7]. However, the HEI-2005 cannot be used for the Dutch situation, because the American dietary guidelines are

\section{Biomed Central}


different from those in the Netherlands. The 2005 Dietary guidelines for Americans, on which the HEI-2005 is based, mention all the major food groups while the Dutch guidelines do not. Furthermore, the Dutch guidelines include a restriction on the number of consumption occasions with acidic drinks and foods (ADF) [5].

To date, two Dutch indices have been developed by Löwik et al. [14], both based on the Dutch Guidelines for a Healthy Diet of 1986. The first dietary quality index consisted of five criteria: less than 35\% energy from total fat, less than $10 \%$ energy from saturated fatty acids (SFA), less than $33 \mathrm{mg} / \mathrm{MJ}$ cholesterol, more than 50\% energy from carbohydrates and less than 25\% energy from mono- and disaccharides. For each criterion, one point was assigned to individuals who adhered. The score, ranging from zero (low quality) to five (high quality), was inversely related to energy intake and positively associated with a higher prevalence of following a prescribed diet and a higher educational level [14]. The second index was a food-based dietary guideline index with seven components. The score, ranging from zero (low quality) to seven (high quality), was positively associated with energy intake and all evaluated nutrient densities (calcium, iron, vitamin A, thiamin, riboflavin, vitamin B6 and vitamin C) [14].

In 2006, the Dutch Guidelines for a Healthy Diet were revised by the health Council of the Netherlands by adding new guidelines on physical activity, number of consumption occasions with ADF and excluding the guidelines on cholesterol and mono- and disaccharides [5]. Furthermore, evidence-based quantitative recommendations for vegetable, fruit, fish, trans fatty acids (TFA), and alcohol consumption were formulated. The guideline for ADF is added to the guidelines in view of the prevention of dental caries and risk reduction of dental erosion. Due to the revision of the Dutch guidelines, no Dutch index is yet available. Therefore, we developed a new index, the Dutch Healthy Diet index (DHD-index), based on the Dutch Guidelines for a Healthy Diet of 2006 [5], the official background document [15] and the information provided by the Netherland Nutrition Centre (NNC) [16]. Furthermore, we applied the index to data of the Dutch National Food Consumption Survey of 2003 (DNFCS-2003) to examine the associations with micronutrient intakes. We hypothesized that participants with higher DHD-index scores will have both higher intakes of vitamins and minerals and have a more nutrient-dense diet.

\section{Materials and Methods}

The DNFCS-2003 is a population-wide food consumption survey in the Netherlands and has been described in detail elsewhere [17]. Briefly, data were collected in 2003 and respondents $(n=750)$ were men and women aged 19-30 years and randomly selected from a representative consumer panel of households. One participant was excluded from these analyses due to an incomplete SQUASH, which led to a total of 749 participants. Their dietary intake was assessed by two non-consecutive 24hour recalls administered by telephone using Epic-Soft. EPIC-Soft is a computerized 24-hour recall program that follows standardized steps $[18,19]$. Recall days were randomly selected from all days of the week. Characteristics of the recall days such as following a diet regime and special day were asked during the 24-hour recalls. In addition, a baseline questionnaire was administered on subjects' characteristics (weight, height, age, education, and income) and demographics (postal code), and the short questionnaire to assess health enhancing physical activity (SQUASH) was administered. Furthermore, a food frequency questionnaire (FFQ) was included to assess consumption frequencies of episodically consumed foods (e.g. fish, eggs, chips). After data collection, macronutrient and micronutrient intakes were estimated by using the Dutch food composition database of 2001 [20]. We selected the micronutrients calcium, folate, iron, magnesium, potassium, riboflavin, thiamin, vitamin A, vitamin B6, vitamin B12, vitamin $C$ and vitamin $E$ by relevance and availability in the database [16,21]. Furthermore, a quality check was done on inconsistencies between first and second interview on general data as birth date. Differences in energy ratio between interviewers and weeks of data collection were checked by using the estimated energy intake divided by estimated basal metabolic rate. Missing values, false answers (that were not in range of possible answers) and typing errors were changed in EPIC soft using the original recall data. Underreporting, based on the estimated energy intake divided by estimated basal metabolic rate, was observed to be $11 \%$.

\section{Development of the DHD-index}

The DHD-index is a continuous score with ten components that represent the ten Dutch Guidelines for a Healthy Diet of 2006 (Table 1). By choosing a continuous scoring system we assume that we can observe changes in diets of intervention studies better than with a dichotomous scoring system. For all components a maximum of ten points can be allotted, resulting in a range of zero to 100 points. The components physical activity, vegetable, fruit, fish, and fiber are adequacy components and the components SFA, TFA, number of consumption occasions of ADF, sodium and alcohol are moderation components. Cut-off values represent the required amount of consumption or physical activities undertaken (minimum for adequacy and maximum for moderation components), whereas the threshold values represents the level of intake that deserves zero points 


\author{
Table 1 Components and Dutch dietary guidelines of the DHD-index and their cut-off (maximum score) and threshold \\ values (minimum score)

\begin{tabular}{|c|c|c|c|c|}
\hline & Components & Dutch Guidelines for a Healthy Diet & $\begin{array}{l}\text { Minimum } \\
\text { score }(=0)\end{array}$ & $\begin{array}{l}\text { Maximum } \\
\text { score }(=10)\end{array}$ \\
\hline 1. & Physical activity (week) & $\begin{array}{l}\text { At least } 30 \text { minutes of moderate intensity physical activity - } \\
\text { brisk walking, cycling, gardening, etc. - at least five days } \\
\text { a week, but preferably every day. }\end{array}$ & 0 activities $^{*}$ & $\geq 5$ activities \\
\hline 2. & Vegetable (day) & Eat 150 to 200 grams of vegetables. & 0 gram & $\geq 200$ gram \\
\hline 3. & Fruit + fruit juices (day) $)^{*}$ & Eat 200 grams of fruit a day. & 0 gram & $\geq 200$ gram \\
\hline 4. & Fiber (day) & $\begin{array}{l}\text { Eat } 30 \text { to } 40 \text { grams a day of dietary fiber, especially from sources } \\
\text { such as fruit, vegetables and whole-grain cereal products. }\end{array}$ & $0 \mathrm{gram} / 4.2 \mathrm{MJ}$ & $\geq 14 \mathrm{gram} / 4.2 \mathrm{MJ}$ \\
\hline 5. & Fish (day) ${ }^{\dagger}$ & $\begin{array}{l}\text { Eat two portions of fish a week, at least one of which } \\
\text { should be oily fish. }\end{array}$ & $0 \mathrm{mg} E P A+D H A$ & $\geq 450 \mathrm{mg} E P A+D H A$ \\
\hline 6. & SFA (day) & $\begin{array}{l}\text { Limit saturated fatty acid consumption to less than } \\
10 \text { percent of energy intake. }\end{array}$ & $\geq 16.6$ en\% & $<10$ en\% \\
\hline 7. & TFA (day) & $\begin{array}{l}\text { Limit mono trans-fatty acid consumption to less than } 1 \text { percent } \\
\text { of energy intake. }\end{array}$ & $\geq 1.6$ en\% & $<1$ en\% \\
\hline 8. & ADF (day) & $\begin{array}{l}\text { Limit consumption of foods and beverages that contain easily } \\
\text { fermentable sugars and drinks that are high in food acids, } \\
\text { to seven occasions a day } \\
\text { (including main meals). }\end{array}$ & $>7$ occasions & $\leq 7$ occasions \\
\hline 9. & Sodium (day) & Limit consumption of table salt to 6 grams a day. & $\geq 2.45$ gram & $<1.68$ gram \\
\hline 10. & Alcohol (day) & $\begin{array}{l}\text { If alcohol is consumed at all, male intake should be limited to } \\
\text { two Dutch units ( } 20 \text { gram ethanol) a day and female intake to one. }\end{array}$ & $\begin{array}{l}\text { Male: } \geq 60 \text { grams } \\
\text { Female: } \geq 40 \text { grams }\end{array}$ & $\begin{array}{l}\text { Male: } \leq 20 \text { grams } \\
\text { Female: } \leq 10 \text { grams }\end{array}$ \\
\hline
\end{tabular} \\ SFA = saturated fatty acids, TFA $=$ trans fatty acids, $A D F=$ acidic drinks and foods. \\ "maximum of 100 gram of juice could be included. \\ ${ }^{\dagger}$ EPA and DHA intake from foods and fish oil capsules. \\ the number of consumption occasions was defined as the number of hours where at least one food or drink with a $\mathrm{pH}<5.5$ and total acidity $>0.5 \%$ was \\ consumed.
}

for the moderation components. For the component ADF the threshold value was lower than the recommended maximum of seven ADF consumption occasions. Consequently, this component was scored dichotomously. The components and their cut-off and threshold values are shown in Table 1.

The first component assesses physical activity; the Health Council of the Netherlands recommends being active for minimally 30 minutes of at least moderate intensity for at least five days per week [5]. The second component is based on the recommendation of 150-200 grams of vegetables per day. The higher of the two recommendations was chosen as the cut-off value of the component. The third component is based on the recommendation of 200 grams of fruits per day. The NNC communicates that a maximum of 100 grams can be replaced by fruit juices which naturally contain folate and vitamin $C$ [22]. In the DNFCS-2003 six types of juice complied with the criterion (orange juice with and without pulp, pineapple juice, berry juice, grapefruit juice and mixed fruit juice) and could be included in the fruit group for a maximum of 100 grams in total. The fourth component is based on the recommendation of 30-40 grams of dietary fiber per day. The criterion used was stated in the background document and was 14 grams dietary fiber per $4.2 \mathrm{~mJ}$ per day [15]. The fifth component, fish, is estimated based on the fish fatty acids eicosapentaenoic acid (EPA) and docosahexaenoic acid (DHA), which are likely to be the protective components of fish [15]. At least $450 \mathrm{mg} /$ day of these fish fatty acids are recommended [15] and their intake can be achieved by fish consumption or by using fish oil capsules. Although, fish consumption is preferred by the Health Council of the Netherlands, fish oil capsules are permitted as substitute for fish for people who do not eat fish [23]. Fish oil capsules were assumed to contain $200 \mathrm{mg}$ of fish fatty acids per capsule, based on labeling information of the fish oil capsules available in the Netherlands. The average daily intake of EPA and DHA from the capsules was added to the 2-day average intake of EPA and DHA from fish. The sixth and seventh components were based on the recommendations to consume less than 10 energy percent of SFA and less than one energy percent of TFA respectively. The eighth component is based on the maximum recommended number of ADF consumption occasions which is seven occasions per day including the three main meals. The operational definition of a ADF consumption occasion is every half an hour where a food item or drink with a $\mathrm{pH}$ level lower than 5.5 and a total acidity higher than $0.5 \%$ is consumed [24]. Consumption of less than 2.4 grams of sodium per day, as recommended in the corresponding guideline, is scored in component nine. In the DNFCS and most other studies, no data is available on salt added 
during cooking and at the table. The contribution of sodium of these sources was assumed to be on average about $30 \%$ of total sodium intake, based on available literature [25-27]. Therefore, we lowered the cut-off and threshold value for this component by $30 \%$. The last component, alcohol, is differentiated by sex. For men, the recommendation is to consume maximally two Dutch units of alcohol, and for women to consume maximally one Dutch unit per day. One Dutch unit of alcohol contains 10 grams of ethanol [5].

\section{Scoring}

All scores were based on the 2-days average intake. For the adequacy components, the minimum score of zero was allotted when there was no consumption, or no activity. The scores for the intakes or activities between zero and the cut-off value were calculated by dividing the reported intake or activity, by the cut-off value and subsequently multiplying this ratio by ten. The maximum score of ten points was allotted if the recommended amount of intake, or activities, was achieved.

For the moderation components, we determined threshold values above which to assign the score of zero, because no scientific evidence specifies the quantity of intake that deserves zero points. The threshold values were determined based on the $85^{\text {th }}$ percentiles of the 2-day average intakes of the sample population. For alcohol intake, however, evidence on upper levels is available and we used the criteria for binge drinking as threshold value [28]. Zero points were allotted when reported intakes were above the threshold values. Ten points were allotted when intake were below the cutoff values. The scores for intake between threshold and cut-off value were calculated by dividing the difference between the intake and cut-off value by the difference between threshold and cut-off value, and subsequently multiplying this ratio by ten. Because the score has to decrease when intake increases, the outcome was subtracted from ten. The ADF component was scored dichotomously and only $3.5 \%$ of the population was assigned a score of zero, while all others received a score of ten.

To be able to apply the DHD-index to the data of the DNFCS-2003, two components were adapted due to limitations of the dataset. Firstly, the SQUASH reported activities per week and not per day. Ten points were allotted when five activities per week, meeting the recommendation, were reported. It was not known on how many days these activities were performed. Secondly, the component ADF was redefined as the number of hours during which foods or drinks fulfilling the criterion were consumed, because intake data was available per hour.

\section{Data analysis}

All food and nutrient intakes and number of ADF occasions were averaged over two days before being used to score individual dietary intakes. Sex-specific quintiles of the DHD-index scores were estimated. Means across the quintiles were tested using $\mathrm{P}$ for trend from linear regression analysis. Micronutrient intake was reported with and without total energy adjustment. Adjusted intakes are presented as mean nutrient intakes per $9.8 \mathrm{~mJ}$, which was the average energy intake of the population. For the component fruit, a sensitivity analysis was done by excluding the fruit juices. SAS (version 9.2, SAS Institute, Cary, NC) was used for all calculations and a $P$ value of $<0.05$ was considered statistically significant.

\section{Results}

Mean \pm SD age of the population was $25.0 \pm 3.6$ years and did not differ between women and men. BMI was significantly higher for women $(24.5 \pm 4.6)$ compared to men $(23.3 \pm 3.2)$, as was prevalence of supplement use (17.5\% vs. $9.6 \%$ respectively) and following a diet regime (9.9\% vs. $0.9 \%$ respectively). Furthermore, $26.5 \%$ of women were classified as lower educated compared to $18.5 \%$ of men. The distribution of recalls over week and weekend days did not differ between men and women. The mean \pm SD DHD-index score for the total population was $59.2 \pm 11.2$ and it was significantly higher for women than for men (mean difference of 2.4 points; Table 2). Women scored significantly higher on the components physical activity, dietary fiber, sodium and alcohol, whereas men scored significantly higher on the components vegetable, SFA and TFA. No significant differences between men and women were observed for the components fruit, fish and ADF.

\begin{tabular}{|c|c|c|c|c|}
\hline & $\begin{array}{c}\text { Total } \\
(n=749)\end{array}$ & $\begin{array}{c}\text { Men } \\
(n=352)\end{array}$ & $\begin{array}{l}\text { Women } \\
(n=397)\end{array}$ & $\begin{array}{c}\text { P-value } \\
\text { between sex }\end{array}$ \\
\hline DHD-index & $59.2(11.2)$ & $57.8(10.8)$ & $60.4(11.5)$ & 0.002 \\
\hline 1. Physical activity & $9.4(1.9)$ & $9.1(2.3)$ & $9.7(1.4)$ & 0.001 \\
\hline 2. Vegetable & $4.8(2.9)$ & $5.2(2.9)$ & $4.4(2.8)$ & $<0.001$ \\
\hline 3. Fruit & $4.6(3.7)$ & $4.4(3.7)$ & $4.8(3.6)$ & 0.130 \\
\hline 4. Fiber & $6.1(2.3)$ & $5.9(2.3)$ & $6.3(2.3)$ & 0.022 \\
\hline 5. Fish & $1.1(2.4)$ & $1.1(2.4)$ & $1.1(2.3)$ & 0.798 \\
\hline 6. SFA & $5.2(3.5)$ & $5.5(3.4)$ & $4.9(3.5)$ & 0.011 \\
\hline 7. TFA & $7.0(3.9)$ & $7.5(3.6)$ & $6.5(4.0)$ & 0.005 \\
\hline 8. ADF & $9.7(1.8)$ & $9.6(2.0)$ & $9.7(1.6)$ & 0.267 \\
\hline 9. Sodium & $2.4(3.8)$ & $1.1(2.6)$ & $3.6(4.2)$ & $<0.001$ \\
\hline 10. Alcohol & $8.9(2.8)$ & $8.4(3.3)$ & $9.3(2.1)$ & $<0.001$ \\
\hline
\end{tabular}

"independent $t$-test comparing men and women.

$\mathrm{SFA}=$ saturated fat, TFA = trans fatty acids, $\mathrm{ADF}=$ acidic drinks and foods. 
The DHD-index score was normally distributed and ranged from 28.1 to 88.0 in men and from 24.4 to 95.0 in women. All components within the DHD-index showed a significant positive association across the sexspecific quintiles of the index (Table 3). Energy intake was inversely associated with the DHD-index $(\mathrm{P}<0.001$; Table 4). Following a diet regime, prescribed or on own initiative, was positively associated with the DHD-index score $(P=0.005)$. Age, BMI, education and prevalence of supplement use did not show a significant trend across quintiles of the index score.

For the micronutrients calcium, and vitamin E significant inverse associations across sex specific quintiles of the DHD-index scores were observed (Table 5). However, when these intakes were adjusted for mean energy intake these associations disappeared. Riboflavin also showed an inverse association across quintiles of the DHD-index, however, after adjustment for energy intake the association changed to a positive association. For the micronutrients folate, iron, magnesium, potassium, thiamin, and vitamin B6, significant positive associations with the DHD-index score were shown for the energy adjusted intakes, but not for the unadjusted intakes. Vitamin $\mathrm{C}$ was positively associated across the quintiles both in $\mathrm{mg} /$ day and in $\mathrm{mg} / 9.8 \mathrm{~mJ}$.

When as part of a sensitivity analysis fruit intake was estimated excluding the intake of fruit juices, mean intake decreased by 83 grams, and the mean score changed from 4.6 to 3.7 points. In total 139 (18.6\%) subjects adhered to the guideline when fruit juices were included as compared to $106(14.2 \%)$ subjects based on whole fruit consumption only. The correlation between the scores with and without juices was very high $(r=0.91$, $\mathrm{p}<0.001)$.

\section{Discussion}

The DHD-index is capable of ranking participants according to their adherence to the Dutch Guidelines for a Healthy Diet by reflecting variation in the components that constitute the index, except for the component ADF. This component showed a low variation and is consequently not discriminative in ranking subjects according to their adherence to the guidelines. Furthermore, the index score is positively associated with 'following a diet regime' and inversely associated with energy intake, which were not included in the index. Additionally, the DHD-index showed to be a good measure of nutrient density of diets.

The components of the DHD-index were based on three different documents about the guidelines: the guidelines as communicated by the health council of the Netherlands [5], the background document describing the guidelines and the evidence in more detail [15] and the information provided by the NNC [16]. The NNC communicates the guidelines in a more understandable way and provides food-based examples of the dietary guidelines to the general Dutch population and subpopulations. These three documents were more or less comparable to each other and we decided to stay as close as possible to the guidelines, with three exceptions. For the component dietary fiber, the background document indicated an energy-dependent recommendation which was more specific than the range of 30-40 gram mentioned in the guidelines. For the fish component, the background document had a specified recommended amount of fish fatty acids instead of consuming two portions of fish. The third exception was the fruit component, which was based on the recommendations of the NNC [22]. The NNC communicates that 100 grams of

Table 3 Distribution of components scores (means (SD)) across sex-specific quintiles of the DHD-index in 749 Dutch men and women ${ }^{*}$

\begin{tabular}{|c|c|c|c|c|c|c|}
\hline & \multicolumn{5}{|c|}{ Sex-specific quintiles of Dutch Healthy Diet index } & \multirow[b]{2}{*}{$P$ for trend } \\
\hline & $1(n=148)$ & $2(n=150)$ & $3(n=151)$ & $4(n=149)$ & $5(n=150)$ & \\
\hline DHD-index & $43.8(5.2)$ & $52.9(2.2)$ & $58.7(2.1)$ & $65.2(2.6)$ & $75.0(4.9)$ & $<0.001$ \\
\hline 1. Physical activity & $8.7(2.8)$ & $9.5(1.6)$ & $9.5(1.6)$ & $9.5(1.9)$ & $9.8(1.0)$ & $<0.001$ \\
\hline 2. Vegetable & $3.5(2.6)$ & $4.3(2.5)$ & $4.6(2.8)$ & $5.1(2.9)$ & $6.6(2.8)$ & $<0.001$ \\
\hline 3. Fruit & $2.1(2.5)$ & $3.4(3.1)$ & $3.9(3.5)$ & $5.7(3.5)$ & $7.8(2.9)$ & $<0.001$ \\
\hline 4. Fiber & $4.5(1.8)$ & $5.0(1.7)$ & $6.1(2.0)$ & $6.7(2.2)$ & $8.1(1.9)$ & $<0.001$ \\
\hline 5. Fish & $0.6(1.4)$ & $0.8(1.8)$ & $0.8(1.8)$ & $1.3(2.6)$ & $2.0(3.4)$ & $<0.001$ \\
\hline 6. SFA & $3.3(3.6)$ & $3.9(3.3)$ & $4.8(3.1)$ & $6.1(3.0)$ & $7.6(2.6)$ & $<0.001$ \\
\hline 7. TFA & $3.8(4.0)$ & $5.8(4.0)$ & $7.7(3.5)$ & $8.3(2.8)$ & $9.3(2.1)$ & $<0.001$ \\
\hline 8. ADF & $8.9(3.1)$ & $9.8(1.4)$ & $9.9(1.1)$ & $9.7(1.6)$ & $9.9(0.8)$ & $<0.001$ \\
\hline 9. Sodium & $0.7(2.1)$ & $1.8(3.3)$ & $2.3(4.2)$ & $3.3(4.2)$ & $4.0(4.3)$ & $<0.001$ \\
\hline 10. Alcohol & 7.7 (3.7) & $8.5(3.2)$ & $9.0(2.6)$ & $9.4(1.9)$ & $9.8(0.9)$ & $<0.001$ \\
\hline
\end{tabular}

*cut-off quintiles men: $47.7,54.9,60.6,67.2$.

cut-off quintiles women: 50.4, 56.5, 62.8, 70.6.

SFA = saturated fat, TFA = trans fatty acids, $\mathrm{ADF}=$ acidic drinks and foods. 
Table 4 Distribution of characteristics (means (SD)) across sex-specific quintiles of the DHD-index in 749 Dutch men and women*

\begin{tabular}{|c|c|c|c|c|c|c|}
\hline & & Sex-specific & es of Dutch & Diet index & & \\
\hline & $1(n=148)$ & $2(n=150)$ & $3(n=151)$ & $4(n=149)$ & $5(n=150)$ & $P$ for trend \\
\hline Age (y) & $24.8(3.7)$ & $25.1(3.5)$ & $24.8(3.5)$ & $24.7(3.5)$ & $25.4(3.7)$ & 0.346 \\
\hline $\mathrm{BMI}\left(\mathrm{kg} / \mathrm{m}^{2}\right)$ & $23.9(3.9)$ & $24.1(4.2)$ & $23.6(4.2)$ & $24.1(3.9)$ & $24.0(3.9)$ & 0.799 \\
\hline Energy intake (MJ/day) & $11.1(3.5)$ & $10.4(3.2)$ & $9.8(3.0)$ & $9.3(3.0)$ & $8.3(2.7)$ & $<0.001$ \\
\hline Supplements (\%) & 28.2 & 20.8 & 32.5 & 24.7 & 29.3 & 0.750 \\
\hline Diet regime $^{\dagger}(\%)$ & 2.0 & 5.4 & 10.6 & 4.6 & 12.0 & 0.005 \\
\hline Education ${ }^{*}(\%)$ & & & & & & 0.059 \\
\hline Low & 25.7 & 28.0 & 23.8 & 20.8 & 15.2 & \\
\hline Moderate & 44.6 & 46.7 & 44.4 & 55.0 & 50.1 & \\
\hline High & 29.7 & 25.3 & 31.8 & 24.2 & 33.8 & \\
\hline
\end{tabular}

*cut-off quintiles men: 47.7, 54.9, 60.6, 67.2.

cut-off quintiles women: $50.4,56.5,62.7,70.6$.

${ }^{\dagger}$ Diet regime: Salt restriction, fat/cholesterol restriction, diabetes, energy restricted, energy restricted (own initiative), light digestible, lactose restricted, vegetarian (no meat/fish), antroposophical, other.

How education=primary school, vocational and lower general secondary education. Moderate=higher secondary education and intermediate vocational training. High=higher vocational education and university.

fruit can be replaced by all fruit juices complying to the criteria of naturally containing vitamin $\mathrm{C}$ and folate [22]. The sensitivity analysis showed that the total scores increased by an average of 0.86 after the inclusion of fruit juices.

For the threshold values of the moderation components, the $85^{\text {th }}$ percentiles of the current population were used, as was done by others [11]. Although we used the $85^{\text {th }}$ percentiles of the 2-day average, the HEI-2005 used the 1-day distribution [11]. Also other indices, such as the heart disease prevention eating index [29] and the Mediterranean diet score [30], used the distribution of intake of the population under study for determining cut-off values. However, because of the use of the $85^{\text {th }}$ percentiles of the distribution of the 2-day averages of 19-30-year-olds, the results of the DHD-index cannot be compared with other Dutch subpopulations, as the cutoff values will differ. An evidence-based threshold value for all moderation components, like the binge-drinking threshold values for the alcohol component, would be the most preferred. However, for the other moderation components these do not exist. Yet, a more appropriate solution would be to use $85^{\text {th }}$ percentiles of usual or long-term intakes of a reference dataset representative of the total Dutch population for all future use.

All ten components of the DHD-index have similar weights, as mentioned in the guidelines [5]. However, some components were correlated, which indicates an overlap in dietary behaviors which causes indirectly more weight to that dietary behavior. The components vegetables and fruit were correlated to the dietary component fiber ( $r=0.36$ and $r=0.32$, respectively), which can be explained by the fact that fiber represents consumption of vegetables and fruit in addition to wholegrain products. The correlation between the component SFA and TFA was 0.29 , which is plausible as these fatty acids appear partly in the same products [15,31]. These correlations should be studied in future research to explore the effect of the additional weight on diet-disease relations. If judged necessary, differential weighting of the components could be applied.

We hypothesized that participants who adhered to a higher degree to the Dutch Guidelines for a Healthy Diet, have both higher absolute intakes of micronutrients and a more nutrient-dense diet. However, only vitamin $C$ intake increased across quintiles of the DHD-index when energy was not taken into account. The intake of the micronutrients folate, iron, magnesium, potassium, thiamin, riboflavin and vitamin B6 only showed a positive association across quintiles of the DHD-index after adjustment for energy intake. This latter result indicates that participants in the higher quintiles of the DHD-index have a more nutrient-dense composition of the diet. However, they have a lower absolute intake of these micronutrients, because of the inverse association of energy intake across quintiles of the DHD-index. The intake of calcium, riboflavin, and vitamin $\mathrm{E}$ showed a decline across the quintiles. Nevertheless, the mean average intake in all quintiles was still acceptable compared to the recommended average intakes [32], which made the lower intakes less worrisome for public health practices. The inverse association of these three micronutrients disappeared after energy adjustment.

In contrast to energy intake, BMI was not inversely associated with the DHD-index score. This result may be due in part to the self-reported nature of the dietary data, which could invoke underreporting [33]. It can also be 
Table 5 Means (SD) of selected micronutrients across sex-specific quintiles of DHD-index in 749 Dutch men and women*

\begin{tabular}{|c|c|c|c|c|}
\hline \multirow[b]{2}{*}{ Micronutrients (day) } & \multicolumn{3}{|c|}{ Sex-specific quintiles of Dutch healthy diet index } & \multirow[b]{2}{*}{$P$ for trend } \\
\hline & $1(n=148)$ & $3(n=151)$ & $5(n=150)$ & \\
\hline Calcium (mg) & $1744(880)$ & $1632(719)$ & $1414(693)$ & $<0.001$ \\
\hline Folate (mcg) & $169(76)$ & $166(92)$ & $177(91)$ & 0.344 \\
\hline Iron (mg) & $9.3(3.1)$ & $9.8(5.7)$ & $9.1(3.8)$ & 0.999 \\
\hline Magnesium (mg) & $309(126)$ & $299(125)$ & $290(116)$ & 0.257 \\
\hline Potassium (mg) & $3056(1129)$ & $2991(1080)$ & $3036(1096)$ & 0.975 \\
\hline Riboflavin (mg) & $1.5(0)$. & $1.5(0.7)$ & $1.3(0.6)$ & 0.002 \\
\hline Thiamin (mg) & $1.0(0.4)$ & $1.0(0.4)$ & $1.0(0.5)$ & 0.119 \\
\hline Vitamin $\mathrm{A}(\mathrm{RE})^{\dagger}$ & $974(882)$ & $975(1031)$ & $905(775)$ & 0.420 \\
\hline Vitamin B6 (mg) & $1.6(0.8)$ & $1.5(0.7)$ & $1.6(0.7)$ & 0.857 \\
\hline Vitamin B12 (mcg) & $3.8(2.1)$ & $3.6(5.4)$ & $3.2(2.8)$ & 0.118 \\
\hline Vitamin C (mg) & $63(40)$ & $76(48)$ & $108(62)$ & $<0.001$ \\
\hline Vitamin E (mg) & $12.6(7.0)$ & $10.5(5.8)$ & $9.6(5.0)$ & $<0.001$ \\
\hline \multicolumn{5}{|c|}{ Micronutrients per 9.8 MJ (day) } \\
\hline Calcium (mg) & $1598(775)$ & $1739(902)$ & $1786(1086)$ & 0.201 \\
\hline Folate (mcg) & $149(48)$ & $167(71)$ & $211(86)$ & $<0.001$ \\
\hline Iron (mg) & $8.5(2.5)$ & $10.0(6.8)$ & $10.9(3.5)$ & $<0.001$ \\
\hline Magnesium (mg) & $272(64)$ & $303(116)$ & $345(102)$ & $<0.001$ \\
\hline Potassium (mg) & $2718(673)$ & $3039(906)$ & 3649 (1077) & $<0.001$ \\
\hline Riboflavin (mg) & $1.4(0.6)$ & $1.5(0.8)$ & $1.5(0.7)$ & 0.014 \\
\hline Thiamin (mg) & $0.9(0.3)$ & $1.0(0.5)$ & $1.2(0.4)$ & $<0.001$ \\
\hline Vitamin $\mathrm{A}(\mathrm{RE})^{\dagger}$ & $882(770)$ & $987(1001)$ & $1073(894)$ & 0.058 \\
\hline Vitamin B6 (mg) & $1.4(0.4)$ & $1.5(0.7)$ & $1.9(0.6)$ & $<0.001$ \\
\hline Vitamin B12 (mcg) & $3.4(2.1)$ & $3.7(4.3)$ & $3.8(3.2)$ & 0.189 \\
\hline Vitamin C (mg) & $57(40)$ & $79(50)$ & $134(80)$ & $<0.001$ \\
\hline Vitamin E (mg) & $11.1(5.0)$ & $10.3(4.7)$ & $11.2(4.4)$ & 0.952 \\
\hline
\end{tabular}

"cut-off quintiles men: $47.7,54.9,60.6,67.2$.

cut-off quintiles women: 50.4, 56.5, 62.7, 70.6 .

${ }^{\dagger} \mathrm{RE}=$ retinol equivalents.

caused by specific subject characteristics like restrained eating in the higher quintiles of the DHD-index score. This hypothesis can be confirmed by the increasing percentage of participants following a diet regime in the higher quintiles of the DHD-index score. Unfortunately, no data on other subject characteristics as eating behavior or true energy intake was available in the DNFCS2003. In the HEI-2005, energy intake from solid fats, alcoholic beverages, and added sugars is included as component of the index [11]. For the Dutch situation, no operational guideline for energy intake is available. The health council states that the guidelines are meant for the apparently healthy population with a healthy and stable weight. Consequently, no component is constructed for energy intake in the DHD-index. Energy adjustment should be therefore applied when examining diet-disease associations.
The adherence to the physical activity criterion was quite high compared to previously described physical activity levels in the Netherlands [34]. This may be due to a possible over-reporting by using the SQUASH [35], although it is a validated questionnaire for estimating usual physical activity [36]. It was suggested by Ocké et al. [17] that the population under study was slightly different compared to the general Dutch population in the same age category, which may partly explain the high level of physical activity.

The average score of the component ADF ranged from 8.9 to 9.9 across quintiles, consequently, the variation of this component was low $(\mathrm{SD}=1.8)$. Therefore this component is not that discriminative in ranking subjects according to their adherence to the guidelines. The component was included in the Dutch guidelines because it is important for the prevention of teeth erosion, which is 
quite different from the aims for prevention of chronic diseases and nutrient deficiencies of the other recommendations [5]. We advise to adapt or delete the component ADF from the index in future research, if variation in the component appears to be low in other studies as well.

Data on sodium intake is expected to be underestimated through lacking information on sodium added at the dinner table and during cooking. We have tried to correct for this by lowering the guideline by $30 \%$. However, the variation in intake of sodium within the population was ignored by this method, which could have biased the results. Preferably, sodium intake is measured in 24-hour urine samples, which is considered the standard for measuring sodium intake [37].

The estimation of the components of the DHD-index was based on the 2-day average of dietary intake. Although two non-consecutive 24-hour recalls are acceptable for assessing dietary intake on group level [38], the 2-day average will not be a good estimate to assess usual intake distributions for some components, e.g. fish and alcohol, due to a low frequency of consumption. A FFQ designed to assess usual intake could give better estimates for intake of episodically consumed foods. A FFQ, however, is designed for ranking participants according to their intake and not for estimation of absolute intakes [39]. Moreover, a FFQ cannot be used to estimate the component ADF. Statistical models as the MultipleSource-Method or the National Cancer Institute method can be used to estimate usual intake distributions or individual usual intakes [40-45]. However, these statistical models have their limitations as well. Altogether, dietary assessment methods are prone to errors which will be reflected by the estimates of the DHD-index. Therefore, care should be taken when comparing DHD-index scores based on different dietary assessment methods.

\section{Conclusion}

The DHD-index can be used to estimate the adherence to the Dutch Guidelines for a Healthy Diet and is a good measure of nutrient density of diets. In future research the DHD-index can be used as monitoring tool in public health research or as tool for assessing a Dutch dietary pattern and studying diet-health associations.

\section{Abbreviations}

DHD-index: Dutch Healthy Diet-index; DNFCS: Dutch National Food Consumption Survey; SD: Standard Deviation; HEl-2005: Healthy Eating Index2005; TFA: Trans Fatty Acids; NNC: Netherlands Nutrition Centre; SQUASH: Short Questionnaire to Assess health enhancing physical activity; FFQ: Food Frequency Questionnaire; SFA: Saturated Fatty Acids; ADF: Acidic Drinks and Foods; EPA: Eicosapentaenoic Acid; DHA: Docosahexaenoic Acid; BMl: Body Mass Index.

\section{Competing interest}

The authors declare that they have no competing interest.

\section{Acknowledgement}

This study was funded by the Netherlands Organization for Health Research and Development (ZonMW). The sponsor had no role in the conduct of the study; in manuscript conception, statistical analyses, data interpretation, manuscript writing, review or approval of the manuscript.

\section{Authors contributions}

The contributions of the authors were as follows: LL participated in the manuscript conception, statistical analyses, data interpretation, manuscript writing and revising; AG participated in manuscript conception, data interpretation, writing and review; EH, JV and PV contributed to data interpretation and review, EF participated in manuscript conception, data interpretation, writing and review. All of the authors contributed to the critical revision of the manuscript. All authors read and approved the final manuscript.

Received: 22 December 2011 Accepted: 28 June 2012

Published: 20 July 2012

\section{References}

1. Jacobs DR Jr, Tapsell LC: Food, not nutrients, is the fundamental unit in nutrition. Nutr Rev 2007, 65:439-450.

2. Jones-McLean EM, Shatenstein B, Whiting SJ: Dietary patterns research and its applications to nutrition policy for the prevention of chronic disease among diverse North American populations. Appl Physiol Nutr metab 2010, 35:195-198.

3. Kant AK: Dietary patterns and health outcomes. J Am Diet Assoc 2004, 104:615-635.

4. Hu FB: Dietary pattern analysis: A new direction in nutritional epidemiology. Curr Opin Lipidology 2002, 13:3-9.

5. Health Council of the Netherlands: Guidelines for a healthy diet 2006. The Hague: Publication no. 2006/21; 2006

6. U.S. Department of Agriculture and U.S. Department of Health and Human Services: Dietary Guidelines for Americans. Washington, DC: Office USGP 2010.

7. Center for Nutrition Policy and Promotion of US Department of Agriculture: Diet Quality of Americans in 1994-96 and 2001-02 as Measured by the Healthy Eating Index-2005. Nutrition Insight 2008, 37.

8. Clutter Snyder D, Sloane R, Haines PS, Miller P, Clipp EC, Morey MC, Pieper C, Cohen H, Demark-Wahnefried W: The Diet Quality Index-Revised: A Tool to Promote and Evaluate Dietary Change among Older Cancer Survivors Enrolled in a Home-Based Intervention Trial. J Am Diet Assoc 2007 107:1519-1529.

9. Kant AK: Dietary patterns: Biomarkers and chronic disease risk. Appl Physiol Nutr Metab 2010, 35:199-206.

10. Imamura F, Lichtenstein AH, Dallal GE, Meigs JB, Jacques PF: Confounding by dietary patterns of the inverse association between alcohol consumption and type 2 diabetes risk. Am J Epidemiol 2009, 170:37-45.

11. Guenther PM, Reedy J, Krebs-Smith SM: Development of the Healthy Eating Index-2005. J Am Diet Assoc 2008, 108:1896-1901.

12. Guenther PM, Reedy J, Krebs-Smith SM, Reeve BB: Evaluation of the Healthy Eating Index-2005. J Am Diet Assoc 2008, 108:1854-1864.

13. Chiuve SE, Fung TT, Rimm EB, Hu FB, McCullough ML, Wang M, Stampfer MJ, Willett WC: Alternative Dietary Indices Both Strongly Predict Risk of Chronic Disease. J Nutr 2012, 142:1009-1018.

14. Löwik MRH, Hulshof KFAM, Brussaard JH: Food-based dietary guidelines: Some assumptions tested for the Netherlands. Br J Nutr 1999, 81:143-149.

15. Health Council of the Netherlands: Guidelines for a healthy diet 2006 Background document. The Hague: publication no. A06/08; 2006.

16. The Netherlands Nutrition Centre. http://www.voedingscentrum.nl.

17. Ocké MC, Hulshof KFAM, van Rossum CTM: The Dutch national food consumption survey 2003. Methodological issues. Arch Publ Health 2005, 63:227-241

18. Slimani N, Deharveng G, Charrondière RU, van Kappel AL, Ocké MC, Welch A, Lagiou A, van Liere M, Agudo A, Pala V, et al: Structure of the standardized computerized 24-h diet recall interview used as reference method in the 22 centers participating in the EPIC project. Computer Methods programs Biomed 1999, 58:251-266.

19. Slimani N, Ferrari P, Ocké M, Welch A, Boeing H, Van Liere M, Pala V, Amiano P, Lagiou A, Mattisson I, et al: Standardization of the 24-hour diet recall calibration method used in the European prospective investigation 
into cancer and nutrition (EPIC): General concepts and preliminary results. Eur J Clin Nutr 2000, 54:900-917.

20. Stichting NEVO: Dutch food consumption table 2001. NEVO-tabel ed. The Haque: Dutch Nutrition Centre; 2001.

21. Fransen HP, Waijers PMCM, Jansen EHJM, Ocké MC Voedingsstatusonderzoek binnen het nieuwe Nederlandse voedingspeilingsysteem. Bilthoven 2005, 350050002(2005).

22. The Netherlands Nutrition Centre. http://www.voedingscentrum.nl/nl/etengezondheid/gezond-eten/vakken-schijf-van-vijf/vak-1-groente-en-fruit.aspx? highlight=keuzetabel+groente+en+fruit.

23. Health Council of the Netherlands: Guidelines for a healthy diet 2006 Background document. The Hague: publication no. A06/08: 48; 2006.

24. El Aidi H, Bronkhorst EM, Huysmans MCDNJM, Truin GJ: Multifactorial analysis of factors associated with the incidence and progression of erosive tooth wear. Caries Research 2011, 45:303-312.

25. Health Council of the Netherlands: Salt and blood pressure. The Hague: publication no. 2000/13; 2000.

26. Mattes RD, Donnelly D: Relative contributions of dietary sodium sources. J Am Coll Nutr 1991, 10:383-393.

27. Ministerie van Volksgezondheid Welzijn en Sport en ministerie van Landbouw Natuur en Voedselkwaliteit: Gezonde voeding, van begin tot eind. The Hague: Nota voeding en gezondheid; 2008.

28. Trimbos institute. http://www.alcoholinfo.nl/index.cfm?act=esite. tonen\&pagina $=203$.

29. Lee S, Harnack L, Jacobs DR Jr, Steffen LM, Luepker RV, Arnett DK: Trends in Diet Quality for Coronary Heart Disease Prevention between 1980-1982 and 2000-2002: The Minnesota Heart Survey. J Am Diet Assoc 2007. 107:213-222.

30. Trichopoulou A, Costacou T, Bamia C, Trichopoulos D: Adherence to a Mediterranean diet and survival in a Greek population. New Engl J Med 2003, 348:2599-2608.

31. Hulshof KFAM, Van Erp-Baart MA, Anttolainen M, Becker W, Church SM Couet C, Hermann-Kunz E, Kesteloot H, Leth T, Martins I, et al: Intake of fatty acids in Western Europe with emphasis on trans fatty acids: The TRANSFAIR study. Eur J Clin Nutr 1999, 53:143-157.

32. Health Council of the Netherlands: Towards an adequate intake of vitamins and minerals. The Hague: publication no. 2009/06; 2009

33. Johansson L, Solvoll K, Bjørneboe GEA, Drevon CA: Under- and overreporting of energy intake related to weight status and lifestyle in a nationwide sample. Am J Clin Nutr 1998, 68:266-274.

34. Wendel-Vos GCW: http://www.nationaalkompas.nl/gezondheidsdeterminanten/ leefstij//ichamelijke-activiteit/hoeveel-mensen-zijn-voldoende-lichamelijk-actief.

35. Kwak L, Kremers SPJ, Brug J, Van Baak MA: Measuring physical activity in field studies: Comparison of a questionnaire, 24-hour recall and an accelerometer. Eur J Sport Sci 2007, 7:193-201.

36. Wendel-Vos GCW, Schuit AJ, Saris WHM, Kromhout D: Reproducibility and relative validity of the short questionnaire to assess health-enhancing physical activity. J Clin Epi 2003, 56:1163-1169.

37. Brown IJ, Tzoulaki I, Candeias V, Elliott P: Salt intakes around the world: implications for public health. Int J Epidemiol 2009, 38:791-813.

38. Crispim SP, de Vries JHM, Geelen A, Souverein OW, Hulshof PJM, Lafay L, Rousseau AS, Lillegaard ITL, Andersen LF, Huybrechts I, et al: Two nonconsecutive $24 \mathrm{~h}$ recalls using EPIC-Soft software are sufficiently valid for comparing protein and potassium intake between five European centres - results from the European Food Consumption Validation (EFCOVAL) study. Br J Nutr 2010, 105:1-12.

39. Siebelink $E$, Geelen A, de Vries JHM: Self-reported energy intake by FFQ compared with actual energy intake to maintain body weight in 516 adults. Br J Nutr 2011, 106:1-8.

40. Dodd KW, Guenther PM, Freedman LS, Subar AF, Kipnis V, Midthune D, Tooze JA, Krebs-Smith SM: Statistical Methods for Estimating Usual Intake of Nutrients and Foods: A Review of the Theory. J Am Diet Assoc 2006, 106:1640-1650.

41. Kipnis V, Midthune D, Buckman DW, Dodd KW, Guenther PM, Krebs-Smith SM, Subar AF, Tooze JA, Carroll RJ, Freedman LS: Modeling data with excess zeros and measurement error: Application to evaluating relationships between episodically consumed foods and health outcomes. Biometrics 2009, 65:1003-1010.

42. Tooze JA, Kipnis V, Buckman DW, Carroll RJ, Freedman LS, Guenther PM, Krebs-Smith SM, Subar AF, Dodd KW: A mixed-effects model approach for estimating the distribution of usual intake of nutrients: The $\mathrm{NCl}$ method. Stat Med 2010, 29:2857-2868.

43. Tooze JA, Midthune D, Dodd KW, Freedman LS, Krebs-Smith SM, Subar AF, Guenther PM, Carroll RJ: A new statiscial method for estimating the usual intake of episodically consumed foods with application to their distribution. J Am Diet Assoc 2006, 106:1575-1587.

44. Haubrock J, Nöthlings U, Volatier JL, Dekkers A, Ocké M, Harttig U, Illner AK, Knüppel S, Andersen LF, Boeing $H$ : Estimating usual food intake distributions by using the multiple source method in the EPIC-Potsdam calibration study. J Nutr 2011, 141:914-920.

45. Zhang S, Midthune D, Guenther PM, Krebs-Smith SM, Kipnis V, Dodd KW, Buckman DW, Tooze JA, Freedman LS, Carroll RJ: A new multivariate measurement error model with zero-inflated dietary data, and its application to dietary assessment. Annals of Applied Statistics 2011, 5:1456-1487.

doi:10.1186/1475-2891-11-49

Cite this article as: van Lee et al:: The Dutch Healthy Diet index (DHDindex): an instrument to measure adherence to the Dutch Guidelines for a Healthy Diet. Nutrition Journal 2012 11:49.

\section{Submit your next manuscript to BioMed Central and take full advantage of:}

- Convenient online submission

- Thorough peer review

- No space constraints or color figure charges

- Immediate publication on acceptance

- Inclusion in PubMed, CAS, Scopus and Google Scholar

- Research which is freely available for redistribution 